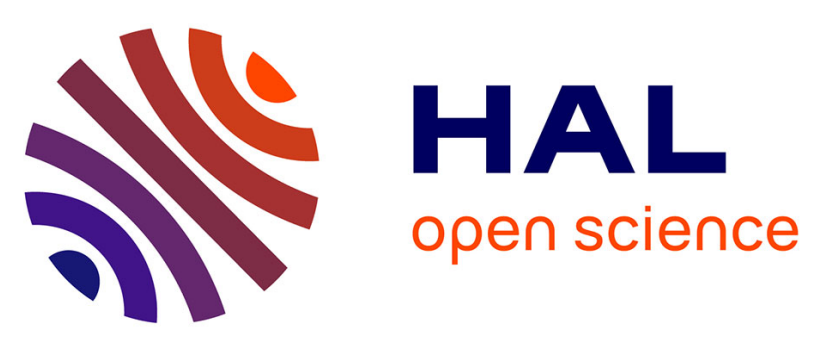

\title{
Experimental demonstration of oxide-mode influence in a dual-purpose oxide-confined vertical-cavity surface-emitting laser resonant detector
}

Véronique Bardinal, Laurent Averseng, Charlotte Bringer, Thierry Camps, J Polesel-Maris, Pascal Dubreuil, Chantal Fontaine, Eléna Bedel-Pereira, Corinne Vergnenegre, A. Muñoz-Yagüe

\section{To cite this version:}

Véronique Bardinal, Laurent Averseng, Charlotte Bringer, Thierry Camps, J Polesel-Maris, et al.. Experimental demonstration of oxide-mode influence in a dual-purpose oxide-confined vertical-cavity surface-emitting laser resonant detector. Applied Physics Letters, 2002, 81 (10), pp.1771-1772. 10.1063/1.1506013 . hal-01158959

\section{HAL Id: hal-01158959 https://hal.science/hal-01158959}

Submitted on 11 Jan 2018

HAL is a multi-disciplinary open access archive for the deposit and dissemination of scientific research documents, whether they are published or not. The documents may come from teaching and research institutions in France or abroad, or from public or private research centers.
L'archive ouverte pluridisciplinaire HAL, est destinée au dépôt et à la diffusion de documents scientifiques de niveau recherche, publiés ou non, émanant des établissements d'enseignement et de recherche français ou étrangers, des laboratoires publics ou privés. 


\title{
Experimental demonstration of oxide-mode influence in a dual-purpose oxide-confined vertical-cavity surface-emitting laser/resonant detector
}

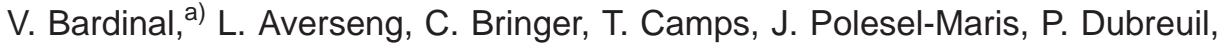 \\ C. Fontaine, E. Bedel-Pereira, C. Vergnenegre, and A. Muñoz-Yagüe \\ LAAS-CNRS 7, avenue du Colonel Roche, 31077 Toulouse, Cedex 4, France
}

(Received 28 May 2002; accepted for publication 18 July 2002)

\begin{abstract}
We report on design, fabrication, and characterization of a vertical-cavity surface-emitting laser (VCSEL) used as a resonant-cavity-enhanced detector for dual-purpose application. The geometry of this oxide-confined VCSEL takes advantage of the properties of the buried oxide layer to allow both single-mode laser emission and detection on a large surface. Here, we demonstrate the presence and the influence of oxide modes in the optical sensitivity spectrum of the device through spatially localized detection measurements. The wavelength of these modes has been correlated to the dip on the reflectivity spectrum measured at the same area of the device surface. (C) 2002 American Institute of Physics. [DOI: 10.1063/1.1506013]
\end{abstract}

The increasing need for high-speed, efficient, compact, and low-cost devices for optoelectronic applications such as bidirectional optical interconnects, optical imaging, or telemetry has recently led to focus on the optimization of dualpurpose vertical-cavity surface-emitting lasers (VCSELs) used as resonant cavity enhanced (RCE) photodetectors. ${ }^{1,2}$ Despite a narrow spectral detection sensitivity due to the high finesse of their cavity, VCSEL diodes are indeed able to efficiently detect light at their resonance wavelength by a simple change in their applied voltage polarity. ${ }^{3-5}$

Here, we present results on design, fabrication, and characterization of an oxide-confined top-emitting VCSEL for both light emission and photodetection at $830 \mathrm{~nm}$ in a singlecavity GaAs-based device. It is now well established that the best performance VCSELs are oxide-confined ones: indeed, the use of a buried oxide aperture close to the cavity allows for the definition of a very low active volume, leading to ultra-low-threshold currents and single-mode emission beams. ${ }^{6,7}$ In our case (Fig. 1), the buried oxide layer is not only used to obtain a high optical quality laser beam but also to enable decoupling between the surface emission, limited by the oxide aperture (diameter $<10 \mu \mathrm{m}$ ), and the surface detection, delimited by the internal diameter of the top electrodes (diameter chosen here to be larger than $50 \mu \mathrm{m}$ ). Indeed, the oxide layer remains transparent to the incoming optical beam and can thus participate in optical detection on a larger area than the emission one. This simple device minimizes optical losses in the detection mode due to the enlargement guided optical system and can be used for half-duplex bidirectional communication links.

However, the optical path change, due to the refractive index difference between the oxidized and nonoxidized zones of the VCSEL, leads to a shift in the wavelength of the Fabry-Pérot cavity mode. ${ }^{8}$ These "oxide modes" have already been reported in oxide-confined VCSELs: ${ }^{9} 10$ these high-order transverse laser modes have been found to be blueshifted from the aimed wavelength and to be highly divergent. We have demonstrated a similar effect in photode-

a)Electronic mail: bardinal@laas.fr tection by means of spatially localized photocurrent and reflectance spectra measurements.

VCSELs have been grown by molecular beam epitaxy under a real-time in situ thickness control ${ }^{11}$ so that the maximum of the gain spectrum of the three GaAs- $\mathrm{Ga}_{0.7} \mathrm{Al}_{0.3} \mathrm{As}$ quantum wells placed at the center of the cavity is perfectly matched to the cavity mode, thus avoiding the formation of oxide modes when laser emission occurs. Oxide-confined devices were then fabricated by reactive ion etching, wet thermal lateral oxidation, polymer planarization, and front and back metallic electrode deposition steps. The thickness of the AlAs layer to be oxidized, located very close to the cavity to avoid lateral current spreading, was intentionally chosen to be equal to a quarter wavelength in order to obtain a strong optical effect on the cavity mode.

The vertical experimental setup for the optical and the electrical characterization of devices before and after mounting is shown in Fig. 2. To achieve spatially localized photocurrent and reflectivity spectra measurements, a tunable titanium:sapphire laser is used. It provides a large spectral range

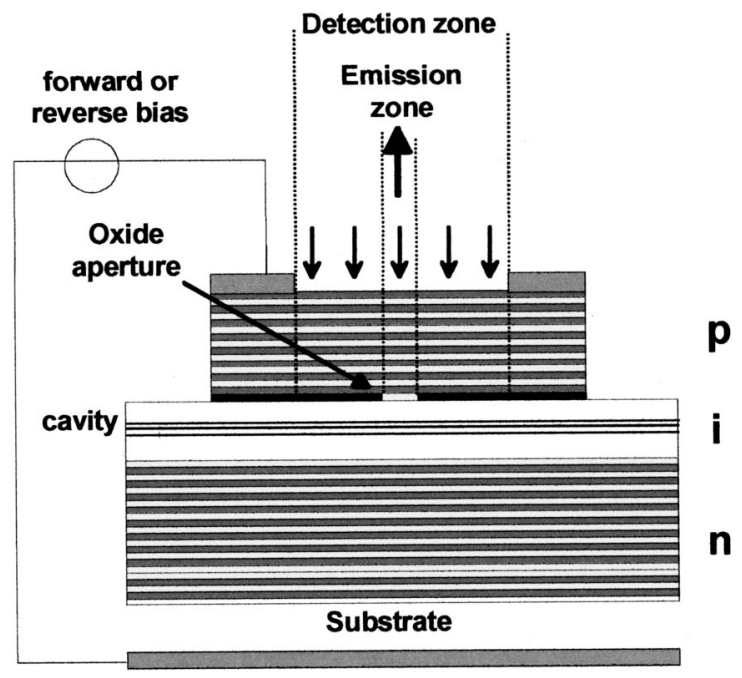

FIG. 1. Description of the single-cavity emitter detector for dual-purpose application. 


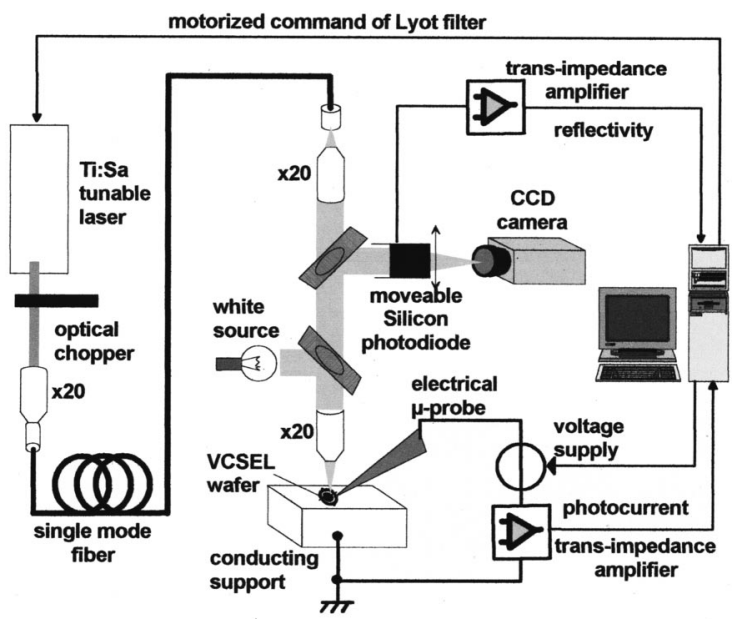

FIG. 2. Experimental setup used for spatially resolved photocurrent and reflectivity spectra measurements.

(750-920 nm) and a spectral resolution better than $0.05 \mathrm{~nm}$. The Ti:Sa laser beam is coupled to a single-mode optical fiber and to an infrared treated $\times 20$ microscope objective in order to obtain a spot diameter as low as $8 \mu \mathrm{m}$ on the surface of the VCSEL, thereby allowing for a spatially resolved analysis of either oxidized and nonoxidized zones. Tuning of the wavelength within the range investigated is achieved by means of a computer-controlled step-by-step motorization of the Lyot filter. The photocurrent is collected and amplified between the two electrodes of the device under zero or reverse bias. The reflectivity is detected by a $\mathrm{Si}$ photodiode. The two resulting signals are demodulated by a lock-in amplifier and acquired by a computer. Photocurrent spectra are normalized by replacing the VCSEL by a reference photodiode and the gold contact pad of the VCSEL is taken as a reference for reflectance normalization.

Photocurrent and reflectivity spectra obtained on nonoxidized (a) and oxidized (b) areas are shown in Fig. 3. At the center of the device, we observe a single detection peak spectrally matched to the emission peak with a maximum sensitivity of $0.18 \mathrm{~A} / \mathrm{W}$, which is independent of the applied reverse bias voltage $(0$ to $-8 \mathrm{~V})$. At the periphery of the

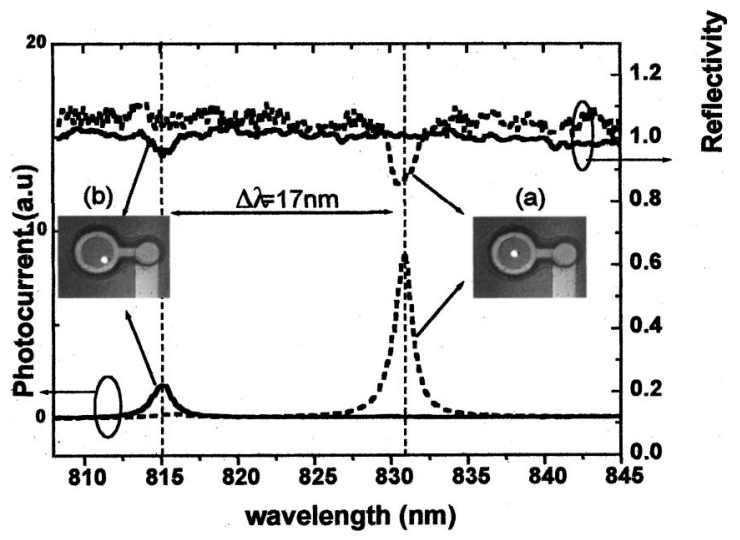

FIG. 3. Photocurrent and reflectivity spectra measured in the emission zone (a) (dashed lines) and in the periphery (b) (solid lines) of the device under a $-5 \mathrm{~V}$ reverse applied voltage. device, a single detection peak is also observed, demonstrating that the photocurrent is correctly collected by the electrodes via the oxide aperture. However, this peak is found to be $17 \mathrm{~nm}$ blueshifted from the central one, thus leading to a five times lower sensitivity. Each detection peak is observed to match the dip of the corresponding reflectivity spectrum. This demonstrates the existence of oxide modes in the lateral zones. It is worthwhile to notice that this effect was observed even though there are no oxide modes in the emission spectrum of the VCSEL. The spectral difference between the two peaks is in good agreement with reflectivity simulations taking into account refractive index values generally used for $\mathrm{Al}_{2} \mathrm{O}_{3}$ thin films. ${ }^{12}$ The misalignment of the quantum well gain and of the cavity mode can thus explain the lower value of sensitivity obtained in the oxidized zones.

In conclusion, we have demonstrated the presence and the influence of oxide modes in oxide-confined VCSELs used as RCE detectors by means of simultaneous spatially localized photocurrent and reflectivity spectra measurements. The observed spectral split between oxidized and nonoxidized zones has been correlated to the reflectivity spectrum. It accounts for the optical cavity length change. This mismatch, which is detrimental to a dual-purpose application, can be reduced to about $3-4 \mathrm{~nm}$ by minimizing the thickness of the oxidized AlAs layer and by placing it at a node of the intracavity optical field as it has been already proposed for oxide-mode suppression for laser emission. ${ }^{9} 10$ However, for photodetection, these oxide modes will not be totally suppressed because there is no gain selectivity. A perfect spectral overlapping between emission and detection on the whole active surface can only be achieved by locally degrading the finesse of the cavity. This can be obtained by etching a few periods of the top Bragg reflector in the oxidized zones. This technology is under study.

The authors wish to thank Michel Fraces and Bruno Duchenne from ONERA, Départment d'Optique Théorique et Appliquée (DOTA) in Toulouse, France, for financial support and technical assistance.

${ }^{1}$ M. S. Ûnlü and S. Strite, J. Appl. Phys. 78, 607 (1995).

${ }^{2}$ C. G. Ortiz, C. P. Hains, J. Cheng, H. Q. Hou, and J. C. Zolper, Electron. Lett. 32, 1205 (1996)

${ }^{3}$ M. Dragas, I. H. White, R. V. Penty, P. J. Heard, and G. Parry, IEEE Photonics Technol. Lett. 11, 1548 (1999).

${ }^{4}$ T. Knöl, H. K. H. Choy, J. L. Pan, R. Ping, R. Jâger, G. Lullo, J. F. Ahadian, R. J. Ram, C. G. Fonstad, and K. J. Ebeling, IEEE Photonics Technol. Lett. 11, 1289 (1999).

${ }^{5}$ L. Georgeon and Y. Boucher, J. Appl. Phys. 85, 3019 (1999).

${ }^{6}$ J. Ko, E. R. Hegblom, Y. Akulova, N. M. Margalit, and L. A. Coldren, Electron. Lett. 33, 1550 (1997).

${ }^{7}$ Y. Hayashi, T. Mukaihara, N. Hatori, N. Ohnoki, A. Matsutani, F. Koyama, and K. Iga, Electron. Lett. 31, 560 (1995).

${ }^{8}$ K. L. Lear, K. D. Choquette, R. P. Schneider, Jr., and S. P. Kilcoyne, Appl. Phys. Lett. 66, 2616 (1995).

${ }^{9}$ K. D. Choquette, K. L. Lear, R. P. Schneider, Jr., and K. M. G. Geib, Appl. Phys. Lett. 66, 3413 (1995)

${ }^{10}$ C. Degen, I. Fisher, W. Elsäßer, L. Fratta, P. Debernardi, G. P. Bava, M. Brunner, R. Hövel, M. Moser, and K. Gulden, Phys. Rev. A 63, 023817 (2001).

${ }^{11}$ F. Van Dijk, V. Bardinal, C. Fontaine, E. Bedel-Pereira, and A. MuñozYague, J. Cryst. Growth 201/202, 1028 (1999).

${ }^{12}$ E. F. Schubert, M. Passlack, M. Hong, J. Mannerts, R. L. Opila, L. N. Pfeiffer, K. W. West, C. G. Bethea, and G. J. Zydzik, Appl. Phys. Lett. 64, 2976 (1994). 